\title{
Breakout Group C: Challenges and solutions for enhanced paleoscience communication
}

Heidi Roop ${ }^{1}$ and Elisabeth Dietze ${ }^{2}$

'Antarctic Research Centre, Victoria University of Wellington, New Zealand; h.roop@gns.cri.nz

${ }^{2}$ Climate Dynamics and Landscape Evolution, German Research Centre for Geosciences, Germany

A the $2^{\text {nd }}$ YSM there was consensus among the young international paleoscientists that there is a great need to better develop skills for communicating with different types of non-academic audiences. Clear and effective communication to the public is becoming increasingly important as current and future climatic and environmental changes are frequently a major focus in the media and politics. However, for the paleoscience community there remains the challenge of properly conveying the concept of past change on longer timescales. Facilitating better public understanding of the scientific process is required to break down barriers and have objective discussions, especially regarding the issue of future climate change.

A productive discussion at the YSM about how to address the challenges we face in communicating paleoscience resulted in two potential solutions:

First, as scientists, we need to be proactive in making our research available in our local communities. Creating connections with internet platforms, classrooms, media outlets and other informal science education venues can be highly productive and rewarding, but also difficult and time consuming to develop. To address this problem and to facilitate paleoscience communication, we propose to link with the PAGES scientist database and outline researchers availability for specific outreach activities (e.g. classroom visits, blog articles, Skype calls, laboratory tours, radio interviews). This type of additional database should be communicated through educational networks such as Polar Education International (PEI). The ultimate hope is that this freely accessible database can begin building lasting relationships between the public and local researchers by making it easy for the public to find local scientists. An encouraging example is the Social Media Knowledge Exchange (www.smke.org), which provides a platform for early career scientists in history and archeology to share their research with non-academic audiences.

Second, the current lack of formal training opportunities in science communication is a major obstacle preventing the effective communication of our research. Coursework and other training opportunities, beyond short workshops, are needed to instruct researchers how to effectively and concisely communicate the significance of their research to any audience. In a highly inter-connected world, it is critical that scientists develop an appropriate level of fluency and understanding of how to use communication tools ranging from social media to informal writing.

Ultimately, communicating our scientific results should become a regular and professionally recognized part of the scientific process. Developing the skills to effectively share our science will undoubtedly increase our broader impacts, and PAGES is in a unique position to facilitate this development in the paleoscience community. Already the YSM has stimulated discussion, and we hope that this dialogue can continue in the broader PAGES network to strengthen and broaden our science communication skills into the future.

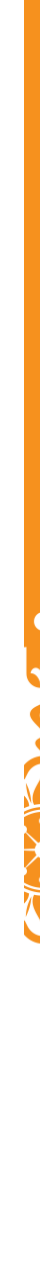

\section{Breakout Group D: Key educational ingredients to ensure the success of future paleoscientists}

\author{
Rajani Panchang ${ }^{1}$ and Julie Richey ${ }^{2}$ \\ 'Agharkar Research Institute, Pune, India; rajanipanchang@gmail.com \\ U.S. Geological Survey, St. Petersburg, USA
}

$T^{n}$ he breakout sessions at the $2^{\text {nd }}$ YSM proved to be an extremely useful exercise that resulted in concrete suggestions for future directions for PAGES and the broader scientific community. The topic of our group was discussed in two subgroups by a total of 21 participants from 12 countries.

One of the key recommendations was that future paleoscience students need better computational skills. In the early days of paleoclimate research, students could turn 50 analyses into a dissertation, but with modern methodological advances, students can now produce hundreds or thousands of geochemical measurements. In addition to expertise in micropaleontology, palynology, organic geochemistry, etc., students need to have the quantitative skills to statistically analyze that data, and effectively put it in the context of a wealth of other paleoclimate archives.

Paleoclimate modelers should have more training in geosciences so that they can better understand the value and limitations of proxy records. Conversely, those generating proxy records need to be capable of understanding and using model results to make proxy-model comparisons.

Students should be encouraged to complete a small research project before opting for a doctoral program so that they can assess their interest as well as aptitude for research. This could be offered as a Bachelor's or Master's dissertation, as is already common practice in some countries, e.g. the USA. This also led to the idea of offering supervisors more incentives (e.g. research assistance or teaching time exemption) for investing time and energy in short-term (i.e. masters-level) research students. Inspired by the panel discussion on peer reviewing, it was also suggested that reviewing should be made a formal part of graduate education.

Over time English has become the single global language bridging international language borders, and thus its knowledge facilitates the effective communication of science. Accordingly, some participants from countries in which English is not the first language did express the need for formal training in reading and writing English. They also wished that some of their science education had been in English.

Earth science is currently not part of the required curriculum in many countries, and the need and importance for elevating earth science education at the primary and secondary school level was expressed. Regarding the much more advanced career stage paleoclimatologists, participants expressed the concern that "paleoclimate" is not as lucrative as mining and petroleum! Although not related to education, the breakout group argued that better incentives and job opportunities will be key conditions to ensure the success of the next generation of paleoscientists. 